\title{
PROGRAMA MINHA CASA MINHA VIDA: UMA ANÁLISE COMPARADA ENTRE CONDOMPINIOS HORIZONTAIS E VERTICAIS EM CURITIBA E FAZENDA RIO GRANDE ${ }^{1}$
}

\author{
Viviane Vidal Pereira dos Santos ${ }^{2}$
}

- Enviado em 20/01/2016

- Aprovado em 21/02/2016

O interesse pelo tema da habitação vem a partir da participação no Programa de Desenvolvimento Urbano e Regional, programa de extensão universitária do curso de Ciências Sociais da Universidade Federal do Paraná, que promove a interdisciplinaridade com os cursos de Informática e Cidadania, Serviço Social e Gestão Ambiental do Campus Litoral da UFPR. No programa foi possível ter contato com teóricos das Ciências Sociais que pensaram os problemas urbanos, bem como com as ações do Estado frente ao problema habitacional em seu contexto atual, com foco na Política de Habitação de Interesse Social (política para famílias de baixa renda e moradores de assentamentos precários ${ }^{3}$ ).

A atual política de habitação vem sendo orientada desde 2009 pelo Programa Minha Casa Minha Vida, criado com o objetivo de equacionar o déficit habitacional no Brasil ${ }^{4}$, além de aquecer a economia por meio da construção civil, dada a emergência da crise econômica mundial em 2008.

\footnotetext{
1 Pesquisa de mestrado em andamento sob a orientação da Professora Doutora Maria Tarcisa da Silva Bega no Programa de Pós-graduação em Sociologia da UFPR.

${ }^{2}$ Graduada em Ciências Sociais pela Universidade Federal do Paraná. Endereço eletrônico: vivivps@ gmail.com.br

${ }^{3}$ Assentamentos precários compreendem favelas, cortiços, loteamentos irregulares de moradores de baixa renda e os conjuntos habitacionais degradados. Apresentam condições de baixa qualidade da estrutura da habitação, adensamento excessivo de moradores, ou ausência de serviços como água potável, saneamento e outros. (Plano Estadual de Habitação de Interesse Social do Paraná, 2013)
}

${ }^{4} \mathrm{O}$ déficit habitacional se refere às deficiências do estoque de moradias, podendo ser em função da precariedade das construções, da coabitação familiar forçada, dos moradores de baixa renda com dificuldades de pagar aluguel e dos que 
O programa orienta também a política de reassentamento habitacional, alternativa nos casos de assentamentos precários. O reassentamento fora bastante utilizado entre as décadas de 1960 e 1970, com o Banco Nacional da Habitação criado na ditadura militar e extinto em 1986 e que de acordo com a literatura sobre habitação o modelo de financiamento e atuação é bastante similar ao PMCMV. Em relação aos reassentamentos, eram alternativas utilizadas para a erradicação de favelas e cortiços nos grandes centros urbanos como uma maneira de "limpar" a cidade. Apresentou experiências negativas na remoção das famílias das áreas, bem como no processo de adaptação, fazendo com que a política de reassentamento fosse reformulada a partir da década de 1980 com o fim do BNH e com a redemocratização, passando seu uso a ser justificado apenas nos casos em que o assentamento apresentar risco ambiental ou em função da construção de grandes obras urbanas que necessite o deslocamento de populações. Outra mudança fundamental foi o acompanhamento das famílias no processo de reassentamento. (DE PAULA, 2010) O Estado se compromete com a entrega da moradia e com o acompanhamento das famílias durante 180 dias após a implantação dos conjuntos habitacionais. Neste período são realizadas avaliações sobre os conjuntos, a qualidade das unidades habitacionais, e também sobre a adaptação das famílias ao novo espaço de moradia.

Com a participação da pesquisadora no PDUR, deu-se início à pesquisa monográfica tendo como interesse principal estudar os conjuntos habitacionais após este processo de acompanhamento do poder público, a pós-ocupação. Pois seria interessante analisar a dinâmica do conjunto em um momento em que os moradores já tivessem desenvolvido suas estratégias de adaptação e de convivência com mais autonomia em relação ao poder público. Passado este processo inicial de acompanhamento, a pergunta que guiou a pesquisa monográfica foi: para além da moradia, dadas as suas antigas condições de habitação, o que muda na vida das famílias reassentadas?

Na monografia foi estudado o conjunto habitacional Jardim Europa em Fazenda Rio Grande, na região metropolitana de Curitiba - PR. Este conjunto foi implantado em 2011 e a pesquisa aconteceu em 2014. Ele atendeu principalmente famílias que moravam em distintos assentamentos precários da região, e também algumas famílias que moravam de aluguel ou de favor, mas que haviam feito cadastro na secretaria de habitação do município e aguardavam o sorteio da casa própria. No total o conjunto habitacional contém 501 moradias, são na maioria sobrados, mas também contém casas que são direcionadas às pessoas idosas ou com deficiência.

De maneira geral, a experiência do Jardim Europa confirma as principais críticas colocadas ao PMCMV no que diz respeito aos empreendimentos construídos para a população de baixa renda,

vivem em casas e apartamentos alugados com grande densidade, e da moradia em imóveis e locais com fins não residenciais. (FUNDAÇÃO JOÃO PINHEIRO, 2013, p.13) 
em relação principalmente à localização dos empreendimentos afastados dos equipamentos e serviços de consumo coletivo. Apesar da conquista da casa própria, muito forte no imaginário brasileiro como uma aspiração, as condições de vida da população são bastante dificultadas em função da distância.

No desenvolvimento da pesquisa algumas questões se mostraram interessantes à pesquisa sociológica, impulsionando o desenvolvimento do projeto de mestrado, como a constituição de relações entre os moradores com o novo espaço, da casa, do conjunto e do bairro; e as relações de vizinhança e sociabilidade.

Como colocado anteriormente, o conjunto estudado na monografia atendeu famílias de assentamentos precários e famílias que já tinham cadastro para receber a casa própria e que não necessariamente moravam antes em assentamentos precários. Foi possível notar, em primeiro lugar, na fala destes últimos um descontentamento em ter que habitar o mesmo espaço com pessoas de áreas de assentamento precário (favelas, áreas de risco ou de invasão), uma vez que a impressão de quem é "de fora" do conjunto é de que o Jardim Europa é um lugar de favelados, sendo que estes moradores não se identificam com tal colocação.

Em segundo lugar, alguns moradores dos assentamentos, na fala deles, contam que viram no Jardim Europa a oportunidade de mudar de vida, de deixar a condição de precariedade e poder habitar em um lugar limpo, que não alaga e onde que é possível organizar a vida. Mas com o passar da convivência no Jardim Europa se incomodaram com a permanência de determinadas práticas dos assentamentos que os desagradavam, como a questão do lixo doméstico nas ruas, problemas com esgoto, o excesso de cachorros soltos na rua e o tráfico de drogas. Eles mostram-se descontentes com aqueles moradores que, de acordo com eles, "trouxeram a favela junto".

Estes dois aspectos ilustram uma tensão nas relações de vizinhança, em que a sociabilidade das famílias se limita ao espaço familiar, pois não querem "se misturar" com os outros, com aqueles que vieram da favela ou que não correspondem as práticas de convivências esperadas para o bem viver no conjunto (separar seu lixo, não abandonar os cachorros na rua, além do trafico de drogas na região).

Por fim, cabe sintetizar o que os dois primeiros aspectos já indicaram, que a visão que se tem do Jardim Europa (isso em relação aos moradores de outros bairros de Fazenda Rio Grande e até de alguns agentes públicos) é de que se trata de uma população favelada, desorganizada, ociosa e violenta. O que, de acordo com Goffman (1982), diz respeito à identidade virtual do conjunto, pois na realidade a pesquisa mostrou, além dos moradores não se identificarem com tal colocação,

\footnotetext{
${ }^{5}$ As aspas dizem respeito às expressões utilizadas pelos moradores entrevistados.
} 
uma heterogeneidade de experiências de vida, de origens, ou seja, distinções sociais que tencionam e contradizem esta identidade.

Estas questões também despertaram o interesse em realizar uma análise comparada em um conjunto habitacional vertical em Curitiba, buscando analisar como se configuram estas relações (vizinhança, sociabilidade e estigma), em conjuntos verticais e se há distinção nestas relações quando se habita um conjunto vertical.

Justificando a necessidade da comparação, uma vez que, seja horizontal ou vertical, a população atendida é de baixa renda, colocam-se duas questões principais. Primeiro, tratam-se de cidades com características e condições distintas. Fazenda Rio Grande é um município da região metropolitana, emancipado recentemente e tem experimentado nos últimos cinco anos um crescimento populacional e imobiliário impulsionado pela política habitacional, uma vez que os terrenos neste município são mais baratos que em Curitiba. Esta, capital do estado, bastante urbanizada, conhecida no imaginário popular como "cidade modelo", "capital ecológica”, em função dos planos de urbanização iniciados nas primeiras décadas do século XX que buscavam justamente tornar Curitiba uma cidade referencial em planejamento urbano, ainda que para tanto boa parte da população pobre e trabalhadora tenha sido colocada à margem deste processo, formando as áreas periféricas da cidade, bem como a região metropolitana de Curitiba. Sendo assim, a pergunta é: existem distinções ou similaridades entre habitar um conjunto habitacional resultante de uma política de reassentamento numa cidade com as características de FRG e habitar um conjunto nas mesmas condições em Curitiba? Existem diferenças no ônus social por morar nestes conjuntos habitacionais? ${ }^{6}$

Em segundo lugar, associada à questão do preço da terra, está a diferença entre conjuntos horizontais, como o Jardim Europa formado por sobrados e casas, e os conjuntos verticais formados por edifícios de apartamentos. Percebe-se um processo de "verticalização" das cidades, em que são preferidas ou valorizadas as construções de prédios por ocuparem uma menor área e ao mesmo tempo permite a construção de um grande número de unidades habitacionais por empreendimento. Este processo gera impactos na dinâmica das cidades, nas leis de uso e expansão do solo urbano, trata-se de um aspecto que será melhor investigado ao longo da pesquisa, mas que já lança a questão, ou uma hipótese, de que também é possível notar distinções entre habitar conjuntos

\footnotetext{
${ }^{6}$ Um conceito importante para se trabalhar nesta questão é o de "ônus social". Kowarick (2000) explica que o ônus social é medido em termos de infraestrutura e serviços públicos, de maneira que quanto maior a infraestrutura e o acesso aos serviços públicos numa determinada área, menor será o ônus por habitar esta região. Em contrapartida, esta área é valorizada e as taxas públicas se elevam, assim como o preço da terra. Neste sentido, as áreas desprovidas de infraestrutura urbana têm o preço da terra mais barato, mas o ônus social é alto.
} 
horizontais e verticais. A primeira vista, apartamentos geram uma proximidade física maior em relação às casas e sobrados, cujo impacto nas relações de vizinhança e sociabilidade podem ser maiores na vida das famílias que vieram de assentamentos. A experiência do Jardim Europa mostrou que algumas estratégias são possibilitadas no conjunto horizontal, como a ampliação da residência para abrigar mais pessoas da família, por exemplo. Então, quais estratégias são traçadas nos conjuntos verticais? Além da vizinhança, uma vez que em um conjunto vertical possibilita o isolamento ou a individualização da família na sua unidade habitacional, com a construção dos muros e portões. Mas como esta as relações de convivência são negociadas nos apartamentos, em que a proximidade física das unidades parece maior? Enfim, estas são algumas questões que se colocam para fundamentar a comparação entre os conjuntos horizontais e verticais.

O conjunto habitacional vertical em que será realizada a pesquisa é o "Vila Mariana", localizado no bairro Tatuquara, ao sul de Curitiba. Este conjunto também foi implantado em 2011, atendendo famílias de demanda aberta e de demanda fechada ${ }^{7}$, com renda até três salários mínimos. Possui ao todo 224 apartamentos. A metodologia utilizada será de base qualitativa, com visitas aos conjuntos habitacionais, entrevistas com famílias e observação participante nos espaços nos possíveis espaços de sociabilidade e organização dos moradores. Terá como apoio a literatura da Sociologia Urbana, da Sociologia do Cotidiano e da Sociologia Política, uma vez que a base do estudo é a ação do Estado frente aos problemas habitacionais, por meio de uma política pública.

Para além das avaliações já realizadas sobre o PMCMV, mostra-se necessário e um estudo junto aos moradores (e até mesmo instituições que recebem novas demandas destes conjuntos habitacionais) para investigar quais os impactos gerados pela política. Além de compreender como as famílias reconstroem suas relações como o espaço e com os demais moradores e como traçam suas estratégias de sobrevivência e adaptação. De maneira geral, espera-se com esta pesquisa contribuir para as avaliações em políticas públicas, políticas habitacionais e desenvolvimento urbano.

\section{REFERÊNCIAS}

COMPANHIA DE HABITAÇÃO POPULAR DO ESTADO DO PARANÁ (COHAPAR). Plano Estadual de Habitação de Interesse Social. PEHIS-PR. Curitiba. 2012.

\footnotetext{
${ }^{7}$ Definição da Companhia de Habitação Popular de Curitiba, em que a demanda aberta diz respeito às famílias com cadastro na Cohab, que aguardam pelo sorteio da casa própria, independente da origem desde que não possua imóvel. Já a demanda fechada diz respeito às famílias moradoras de assentamentos precários.
} 
DE PAULA, F. C. Constituições do habitar: reassentamento do Jd. São Marcos para o Jd. Real. 129 f. Dissertação (Mestrado em Geografia) - Instituto de Geociências, Universidade Estadual de Campinas, São Paulo, 2010.

FUNDAÇÃO JOÃO PINHEIRO (2013). Déficit Habitacional Municipal no Brasil. Fundação João Pinheiro. Centro de Estatística e Informações, Belo Horizonte, 2013. Disponível em: http://www.fjp.mg.gov.br/index.php/docman/cei/deficit-habtiacional/216-deficit-habitacionalmunicipal-no-brasil-2010/file

GOFFMAN, E. Estigma e Identidade Social. In: Estigma: notas sobre a manipulação da identidade. Rio de Janeiro: Zahar, 1982, p.2-50.

KOWARICK, L. Escritos Urbanos. São Paulo, Editora 34, 2000. 